\title{
SPOT WELDING COPPER-1\%CR ELECTRODE TIPS PRODUCED VIA EQUAL CHANNEL ANGULAR PRESSING
}

\author{
L. B. Hussain ${ }^{1}$, A.A. AluUboury ${ }^{2}$, M.A.M. Gebril ${ }^{3}$, Nurulakmal M. Sharif ${ }^{1}$ \\ ${ }^{I}$ School of Materials and Mineral Resources Engineering, Universiti Sains Malaysia, Penang, \\ Malaysia \\ ${ }^{2}$ Department of Physics, Garyounis University, Benghazi, Libya. \\ ${ }^{3}$ Benghazi, Libya
}

\begin{abstract}
A sharp $120^{\circ}$ equal channel angular pressing (ECAP) following route $\mathrm{B}_{\mathrm{C}}$ was applied at room temperature to refine the grain sizes of pure copper and copper$1 \%$ Chromium alloy for spot welding electrode tips application. Initially deformation behavior was investigated with the position using colorful plasticine as work piece followed by copper alloy. It was found that the deformation at the central part of the work piece is heavily sheared than the outer part. Optical and scanning electron microscopy were used to study the progress of grain refining under the influence of rotation and number of passes during pressing. The influence of elongated fibrous nano grains on electrical conductivity and hardness were discussed. Shear test of spot welded 303 stainless steel indicated that nano structural $\mathrm{Cu}-1 \% \mathrm{Cr}$ electrode tips used showed a superior results compared to commercial electrodes.
\end{abstract}

KEYWORDS: Equal channel angular processing (ECAP); Spot welding; Ultra-fine grains, Conductivity, Hardness.

\section{INTRODUCTION}

Severe plastic deformation methods have been the subject of intensive investigations in recent years [1]. It has been proven to be available for producing materials of fine microstructure via a method where large strain can be introduced into a work piece by simple shear deformation without change in the cross sectional area [2-5].

ECAP process, where two equal cross sectional channels intersect at an oblique angle $\Phi$ and $\Psi$ indicates the angle occupied by the curved region at the point of intersection and lies between $\Psi=0$ and $\Psi=\pi-\Phi[6]$. A work piece of almost the same cross section is placed into one of the channels (vertical channel), and a plunger then extrudes it into the second channel. Despite the unique capability of ECAP, primarily it has not been widely used because the strain per pass through the die channels is not very large; therefore to obtain a desire high strain and microstructure by ECAP, many passes are required.

Materials for spot welding electrodes should have sufficiently high thermal and electrical conductivities, and sufficiently low contact resistance, to prevent burning of the work piece surface or alloying of the electrode face with it and should have adequate strength to resist deformation at operating pressures and temperatures. Electrode materials 
have been classified by Resistance Welder Manufacturers Association (RWMA) into two composition groups: copper-based alloys and refractory metal compositions. These classifications cover a wide range of resistance welding electrode materials to meet most applications [7]. In addition to these standard materials, there are a number of unclassified copper alloys and other materials that may be suitable for resistance welding electrodes. Suitability will depend upon the application, although most requirements are met by materials that comply with RWMA standards [8]. Copper is used for electrodes because it has a low resistance and high thermal conductivity compared to most metals.

Unfortunately, when the electrodes get too hot, heat marks on the surface of work pieces can be formed. The electrodes also become susceptible to "mushrooming". Electrode mushrooming reduces their usable lifetime. An attempt to overcome this entire problem is to strengthen copper alloy which can be developed via nano structure. An attractive and viable approach or mechanism for improving the strength of copper is to introduce a fine $\mathrm{Cr}$ structure into $\mathrm{Cu}$ matrix, resulting in a dispersion-strengthened alloy. Copper matrices containing fine dispersions are particularly attractive for their excellent combinations of thermal and electrical conductivities, strength retention at elevated temperature and overall micro structural stability.

In the current study, the deformation behavior of plasticine mainly focused on understanding of local inhomogeneity, during the ECAP process. In particular, the effect of friction conditions on the inhomogeneous deformation of the work piece is described. Subsequently a nano fibrous structural copper chromium alloy can be produced. Properties such as conductivity with low electrical resistance and hardness were also discussed.

\section{MATERIALS AND METHOD}

A die with two intersecting channels of equal cross section is used. A work piece, in the form of a circular cross sections are produced by pressing the work piece in the vertical (entrance) die's channel to fit within the entrance channel of an ECAP die and it is then pressed through the die until it emerges from the exit channel. In this investigation, the pressing condition applied following route $\mathrm{B}_{\mathrm{C}}$, in which after each pass the sample is rotated $90^{\circ}$ clockwise before performing the next pass. According to Segal [9] the shear plane orientation changed with the number of passes and intersection of these shear planes develop an approximate uniform network into the material. Therefore, an equiaxial and ultrafine structures with high angle grain boundaries are attained for route $\mathrm{B}_{\mathrm{C}}$ with lowest number of passes. Thus, route $\mathrm{B}_{\mathrm{C}}$ is more effective and more suitable for grain refinement. Therefore, for each pass the pressed work piece have to be removed from the die, rotate $90^{\circ}$ clockwise and re-insert into the die for the next pass. Under these conditions, the deformation is achieved by simple shear. Deformed by ECAP, the work piece retains the same cross sectional area so that it is able to repeat the process to several cycles. Therefore, every plastic strain could be accumulated in the sample.

The materials used in the present investigation were plasticine, copper and copper$1 \% \mathrm{Cr}$ alloy as work pieces of $10 \mathrm{~mm}$ diameter were subjected to ECAP for several 
extruding passes at room temperature through lubricated tool steel die. ECAP die consisted of two channels at an angle of $\Phi=90^{\circ}$ and $\Psi=0^{\circ}$ as shown in Fig. 1.

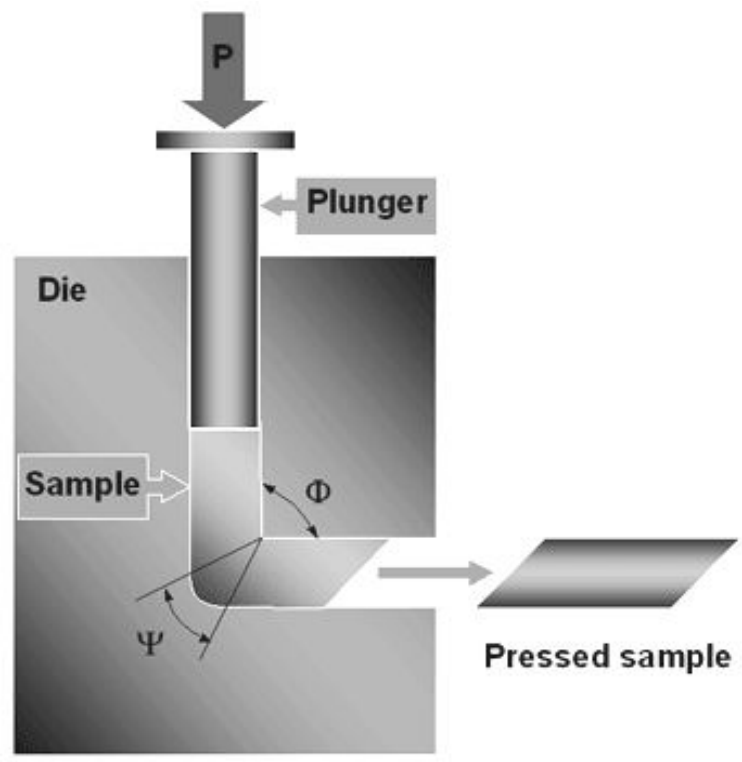

Fig. 1: Angles for equal channel angular pressing and ECAPed workpiece.

The plasticine was made from small equal and colorful plasticine pieces connected to each other under very low pressure to produce $10 \mathrm{~mm}$ cross section plasticine rod in order to simulate the grain structure of polycrystalline structures. The plasticine work pieces were photographed before extrusion through the die and after each required number of passes. Then the deformed trend was investigated.

Pure copper (99.9\%) $10 \mathrm{~mm}$ in diameter and $50 \mathrm{~mm}$ in length, and copper$1 \%$ chromium alloy was prepared via melting and casting, the alloy was fully annealed at $850^{\circ}$ for $1 \mathrm{hr}$ and subsequently machined to rods with dimensions of $10 \mathrm{~mm}$ in diameter and $50 \mathrm{~mm}$ in length for ECAP.

Copper and copper-chromium samples were cut using diamond cutter at transverse and longitudinal directions with respect to pressing direction of plunger side and mounted for polishing and etching. Scanning electron microscopy was conducted and the grain sizes ware observed and size was estimated directly from the grains that have a well-defined grain boundary.

Knoop micro hardness testing with 100 gm were applied at room temperature, the resulting impression was observed under a microscope and measured. The value of hardness was taken as the average of 10 measurement made on the surface of the sample. After the samples at transverse and longitudinal directions were cut, resistivity test was carried out. The test was accomplished by a four point probe. The samples were fabricated into truncated shape before weld test on stainless steel (304) was carried out on the electrodes. This work was done using the lathe machining; coolant is used to avoid the grain growth of samples due to heat generated during machining. The fabricated electrode tips should be fitted well into a modified holder, and the minimum face diameter of electrode with truncated shape was $5 \mathrm{~mm}$. 
Shear test specimens were made from 304 stainless steel samples having dimensions of $0.7 \mathrm{~mm}$ thickness, $16 \mathrm{~mm}$ width and $50 \mathrm{~mm}$ length after surface polishing and cleaning by sand blasting to avoid any hindrance of the current passing. The foot press type spot welding machine was used in this project to joint stainless steel samples, and different welding parameters were used to weld the stainless steel samples to get the best welding property.

\section{RESULTS AND DISCUSSION}

It has been demonstrated that, providing the sample is constrained to fully fill the die channel and the die corner is sharp, on traveling through the die an element will be sheared abruptly by crossing the joint line between the two channels by an amount dependent on the die channel angle [2]. The difference in the deformation behavior within the plasticine sample where a deformation at the central part of the sample is heavily sheared than the outer part is attributed to two reasons. First, the asymmetry of the stress state, where the inner part of the entry side receives compressive stress due to the compression of the ramp, and the outer part of the entry side of the sample is in the tensile stress state since the outer part is elongated in the pressing direction ahead of and in the front part of the main deformation zone (Fig. 2). Second, the less sheared at the outer part is attributed to the friction effect between the sample and the die walls [10]. However, the friction will intensify the shear deformation of the surface elements since the friction operates in the reverse direction to that of the motion of the moving surface. Evidently, the sample deformed in longitudinal fibrous with ultra fine structure in a cross section of the sample. After 12 passes clearly the structures has undergone a severe deformation and ultra fine structure can be seen in Fig.1f. Interestingly this deformation mechanism can be applied on copper and copper alloys for resistance spot welding applications. It may be obvious that hardness and conductivity can be improve since high conductivity and hardness are the critical factors to successful resistance spot welding (RSW) in robotic and automation industries.

The initial grain size of pure copper is about $200 \mu \mathrm{m}$. The two groups were subjected to plastic deformation using the equal channel angular pressing (ECAP) method. During ECAP the direction and number of the billet passes through the channel are very important for microstructure refinement. Therefore, samples were pressed through the die using a plunge, and when each pass is terminated, the samples were rotated about the longitudinal axis by $90^{\circ}$ in the same direction after each consecutive pressing. This rotation procedure was designated as route $\mathrm{Bc}$ and it led most expeditiously to a homogeneous equiaxedgrained structure in transverse toward the pressing [11,12].

Figures 3 (a) and (b) show the microstructure of pure $\mathrm{Cu}$ and $\mathrm{Cu}-1 \% \mathrm{Cr}$ alloy before and after ECAP, respectively. It is observed that the pure copper sample shows defined equal axis grain, while $\mathrm{Cu}-1 \% \mathrm{Cr}$ consisted of copper matrix with eutectic structure (Fig. $3 \mathrm{~b}$ ). It was noted that the change of grains to elongated shape is distinct after four and seven passes of ECAP (Fig. 3c). It is interesting that the eutectic structure is also elongated and disperses as stringers in between the copper matrix. It was believed that deformation of the grain in the direction pressing lead to fibrous tiny grains. Further passes lead to the 
production of nano grains. However, microstructure of $\mathrm{Cu}-1 \% \mathrm{Cr}$ after 7 passes in transverse direction showed equaxis and round eutectic grains (Fig. 2c).

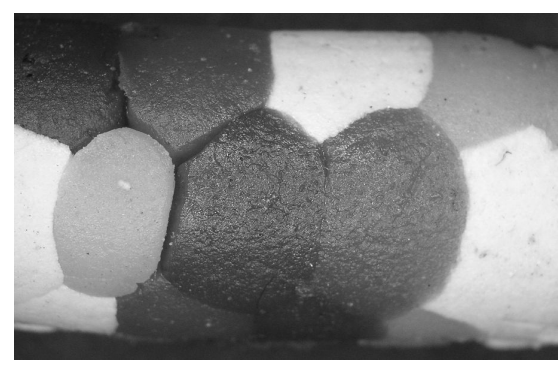

(a)

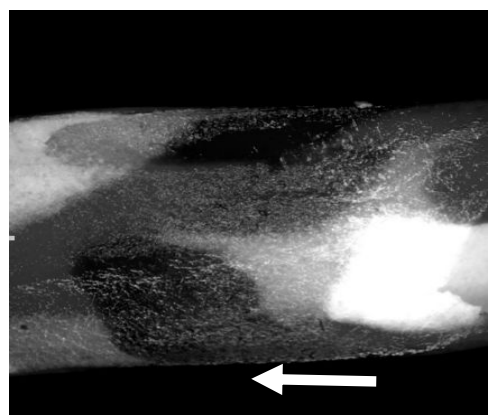

(c)

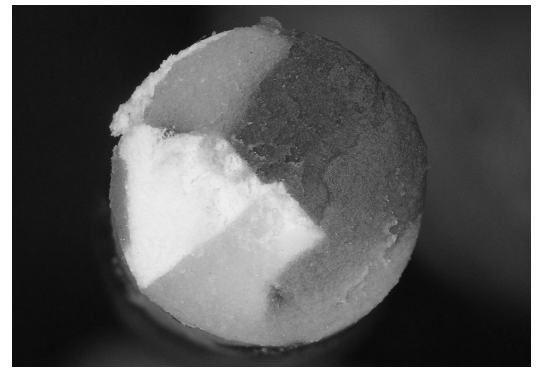

(b)

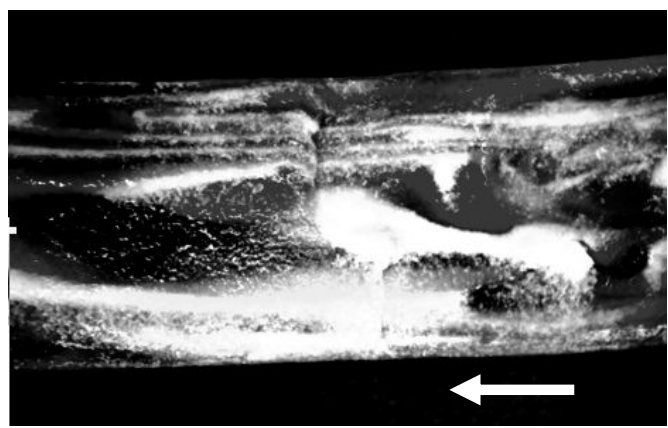

(d)

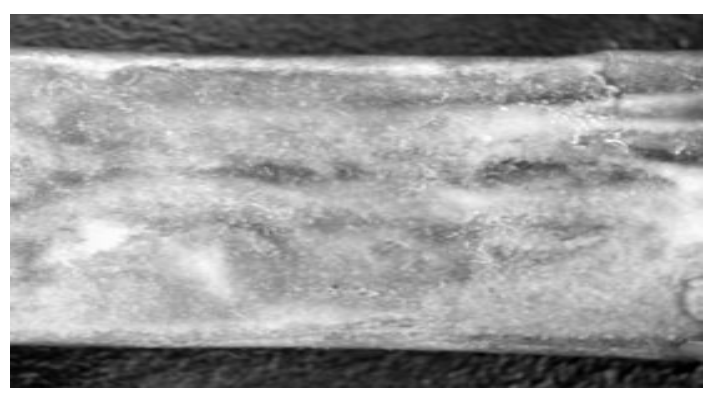

(f)

Fig. 2: ECAP plasticine sample (a) longitudinal simulated grain boundary before pressing, (b) cross section simulated grain boundary before pressing, (c) longitudinal cross section structure after one pass, (d) longitudinal cross section structure after 8 passes and (f) longitudinal cross section structure after 12 passes by using $120^{\circ}$ sharp die (top edgeinner ) and (bottom edge - outer). x10

The Knoop micro hardness measured on the surface of tip clearly indicates that the hardness of pure copper after ECAP is higher than pure copper before ECAP process (Fig. 4). The hardness of copper-chromium was also improved by ECAP process due to ECA process which leads to formation of nano grains. It is believed that ECAP processes enhanced and improved the hardness due to refinement of the grain, which leads to reduction in grain sizes within the submicron or nano range with boundaries having high angles of miss orientation. 


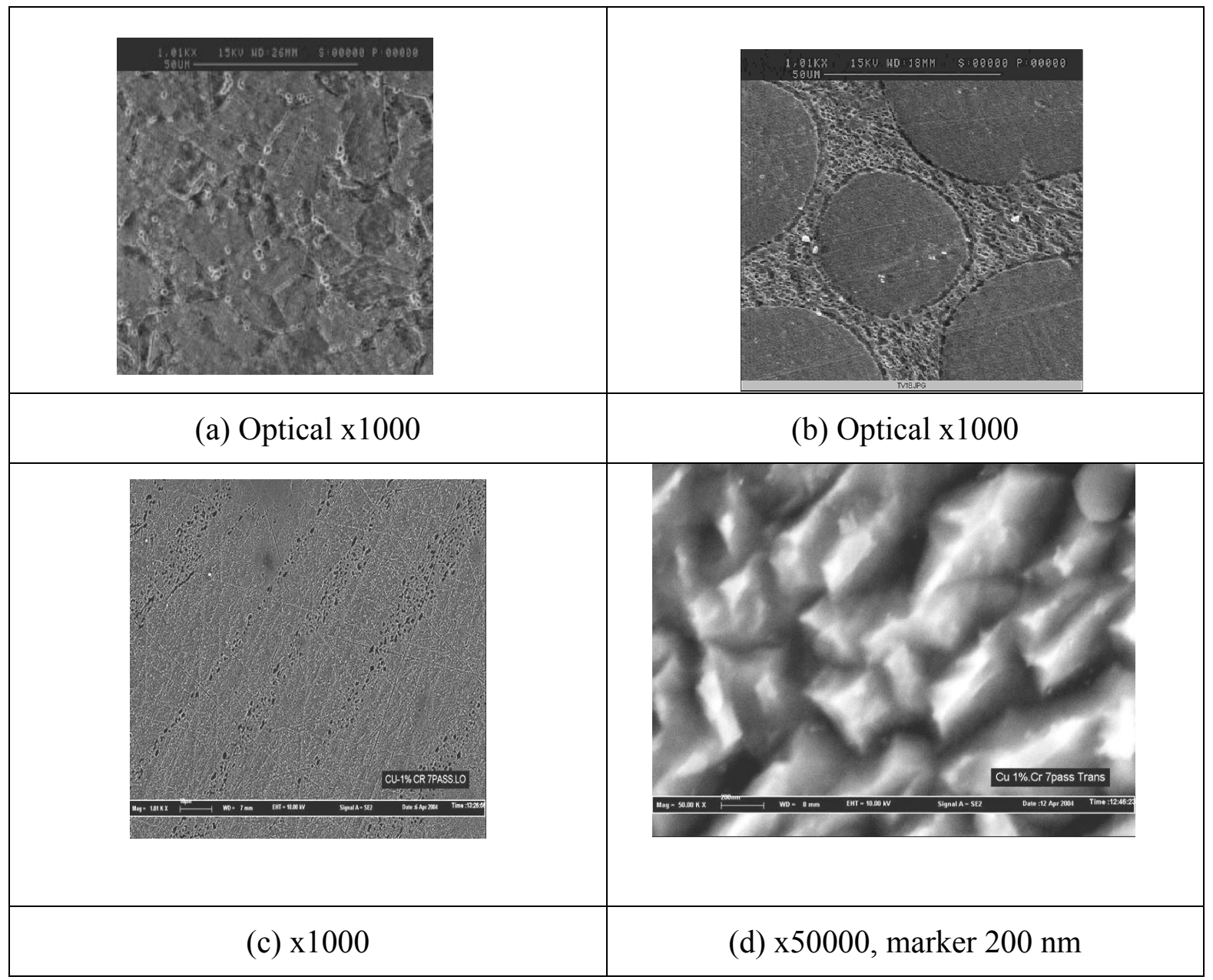

Fig. 3: (a) microstructure of pure $\mathrm{Cu}$ and (b) and (c) longitudinal $\mathrm{Cu}-1 \% \mathrm{Cr}$ alloy before and after ECAP respectively, the arrow indicates the direction of pressing (d) microstructure of $\mathrm{Cu}-1 \% \mathrm{Cr}$ in transverse direction after 7 passes.

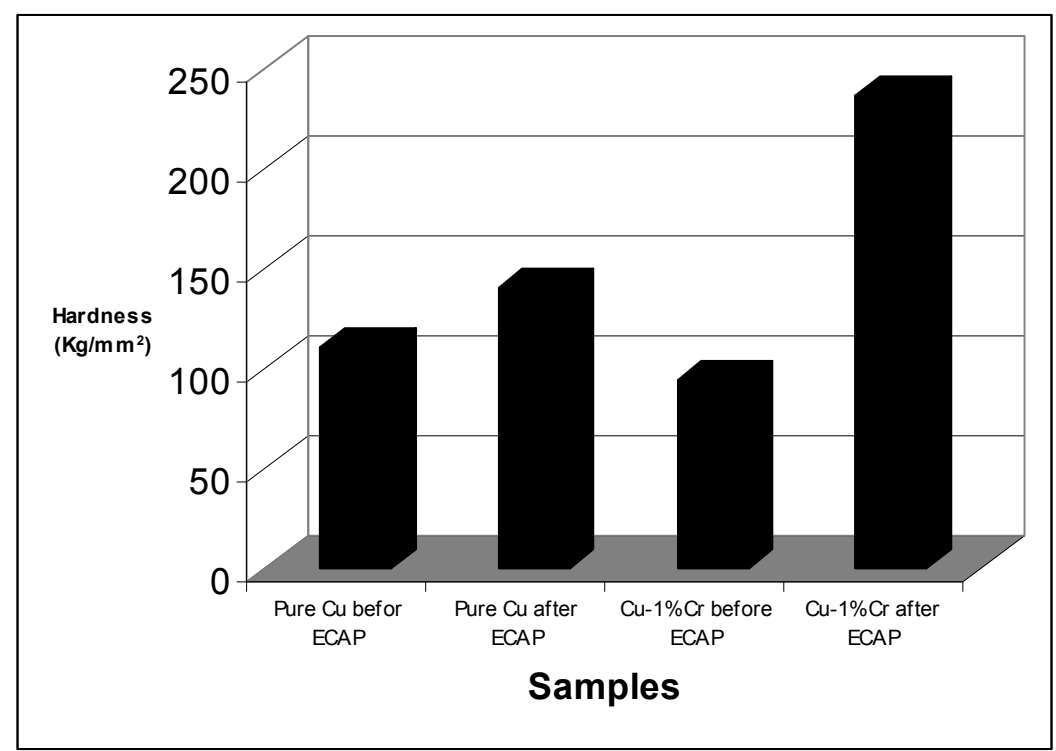

Fig. 4: Knoop hardness results of Pure $\mathrm{Cu}$ and $\mathrm{Cu}-1 \% \mathrm{Cr}$ after and before ECAP. 
Typically, comparison of IACS\% was made between annealed copper to represent the commercial electrodes and $\mathrm{Cu}-1 \% \mathrm{Cr}$ alloy after 4 passes. Figure 5 shows the \%IACS for standard annealed copper at $20^{\circ} \mathrm{C}$ is $100 \%$ IACS and IACS $\%$ of $\mathrm{Cu}-1 \% \mathrm{Cr}$ alloy after 4 passes. Four probe resistivity results analysis indicated that the conductivity of $\mathrm{Cu}-1 \% \mathrm{Cr}$ alloy in the ECAP direction is improved by $10 \%$, due to ECAP processes which lead to formation of longitudinal grains with high angles which act as channels to help in carrying the charge carrier with less scattering. Conductivity enhancement of $\mathrm{Cu}-1 \% \mathrm{Cr}$ alloy after 4 passes ECAP gives good indication to improve the resistance spot welding application beside the improvement of hardness. It has to be mentioned that after 4 passes the conductivity declined due to the presence of nano structure within the longitudinal direction which in turn acts as an obstacle in the current flow leading to increase the resistance.

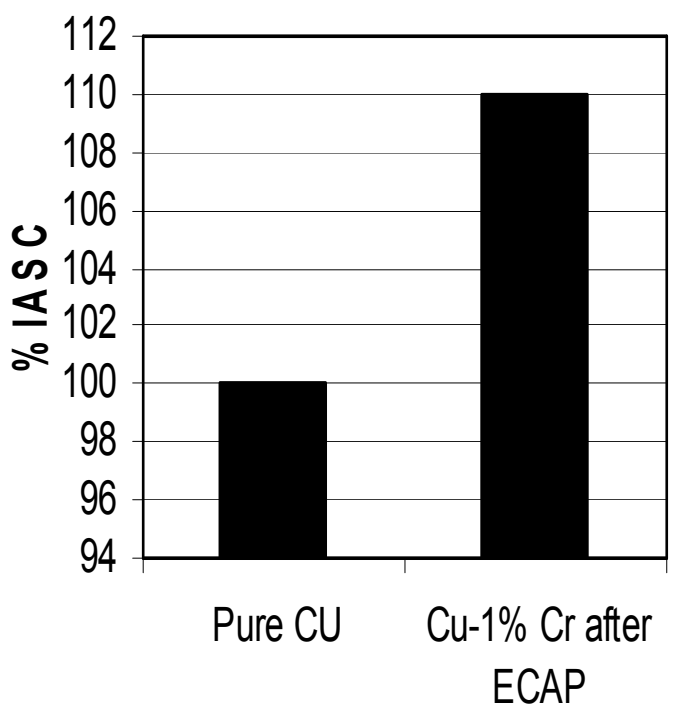

\section{Electrode}

Fig. 5: IACS $\%$ for pure $\mathrm{Cu}$ no passes and $\mathrm{Cu}-1 \% \mathrm{Cr}$ alloy after four passes.

It was shown that shear strength values of welded stainless steel using $\mathrm{Cu}-1 \% \mathrm{Cr}$ electrode tips after 4 passes of ECAP compare to pure $\mathrm{Cu}$ before ECAP and after ECAP, electrodes was improved by $25 \%$ for pure copper and $50 \%$ for $\mathrm{Cu}-1 \% \mathrm{Cr}$ respectively. This is due to the hardness improvement and conductivity. In general the shear strength depends on both the tips contact area and the conductivity, large nugget area with low heat diffusivity leads to low shear stress. As the diameter of nugget increases with proper welding conditions, the load of failure increases and fracture takes place in one of the sheets around the periphery of the weld, leaving the nugget or slug attached to the other sheet (pull-out) failure. The failure leaving the nugget or slug attached to the other sheet interface is noted, which indicates that the diffusion due to the spot welding is good enough leading the shear to take place at heat affected zone circumference around the nugget. 
In general $\mathrm{Cu}-1 \% \mathrm{Cr}$ tips after ECAP showed smaller tip diameter deformation during spot welding, in comparison with $\mathrm{Cu}-1 \% \mathrm{Cr}$ produced tips before ECAP, and pure copper tips, due to formation of nano grains that leads to higher hardness for $\mathrm{Cu}-1 \% \mathrm{Cr}$ tips after ECAP compared to $\mathrm{Cu}-1 \% \mathrm{Cr}$ produced tips before ECAP and pure copper tips. This may lead to longer life for $\mathrm{Cu}-\mathrm{Cr}$ electrode tips produced by ECAP than pure $\mathrm{Cu}$ electrode tips produced without ECAP, and $\mathrm{Cu}-\mathrm{Cr}$ before ECAP electrode tips. As a result, shear stress of welded stainless steel after ECAP tips is higher than welded sample before ECAP process tips. The electrode deformation occurred after each weld attempted. The trend of tips diameter deformation after ECAP was less than that of tips produced before ECAP. Electrode tip diameter increases with a 100 weld number for tips produced before and after ECAP for $\mathrm{Cu}$ electrode tips. The change in diameter was observed to increase by $40 \%$ for electrodes without ECAP application.

Figure 6 shows the complete feature of RSW for stainless steel welds using $\mathrm{Cu}-1 \% \mathrm{Cr}$ electrode tips after 4 passes. Nugget structure is well formed a thin area of heat-affected zone (HAZ) is observed around the nugget area, and indention of the outer surface of sheets was observed. This confirmed that the penetration or the depth that fusion extends into the outer work piece is in the accepted range (20 to 80\%) of the work piece thickness. It showed high shear strength values of welded stainless steel using $\mathrm{Cu}-1 \% \mathrm{Cr}$ electrode tips after 4 passes ECAP compare to pure $\mathrm{Cu}$ before ECAP and after 4 passes ECAP electrodes, this is due to the hardness improvement. Typical shear failure rather detachment was observed, Fig. 6 b.

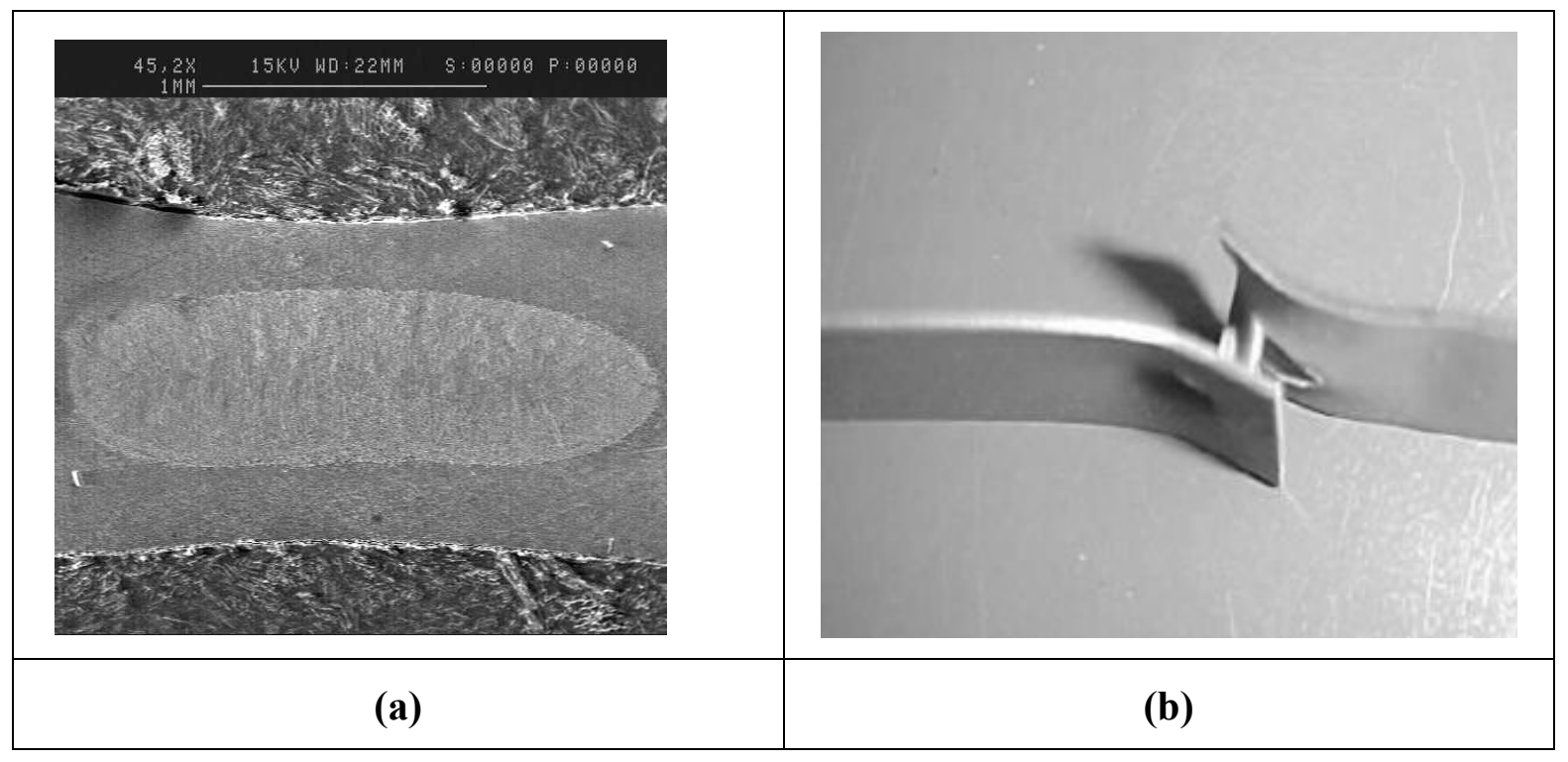

Fig. 6: (a) SEM image that show the features of RSW of stainless steel welds by $\mathrm{Cu}-$ $1 \% \mathrm{Cr}$ electrode tips after 4 passes which are structure of fusion zone (Nugget) formation and very thin HAZ (x25). (b) Maximum shear of spot welded stainless steel failure rather then detachment. 


\section{CONCLUSIONS}

Plasticine was used in order to understand more on the plastic deformation behavior of the polycrystalline material during the ECAP process. It is clearly noticed, the lesser shear deformation zone occurrence near the surface which pass through the outer corner of the die is attributed to the fast move of the outer part of the material compared to the inner part of the material. This deformation mechanism leads to formation of nano fibrous structural grains.

ECAP produces nano elongated grain boundary with fine sub-grain for both $\mathrm{Cu}$ and $\mathrm{Cu}-1 \% \mathrm{Cr}$ ranging from $100-500 \mathrm{~nm}$ for four passes and less than 100 to $300 \mathrm{~nm}$ for seven passes respectively. The hardness of $\mathrm{Cu}-1 \% \mathrm{Cr}$ was improved by ECAP process compared to pure $\mathrm{Cu}$ and $\mathrm{Cu}-1 \% \mathrm{Cr}$ before ECAP process due to formation of ultrafine and nano grains. After 4 passes in ECAP process, the IACS \% of $\mathrm{Cu}-1 \% \mathrm{Cr}$ increased due to formation of longitudinal grains with high angles which act as channel to help in carrying the charge carrier. Shear strength of welded stainless steel produced by $\mathrm{Cu}-1 \% \mathrm{Cr}$ electrode tips after ECAP process higher than that of tips produced before ECAP process. On the other hand, the shear strength of stainless steel welds using $\mathrm{Cu}-1 \% \mathrm{Cr}$ tips shows higher value than welding produced via $\mathrm{Cu}$ tips before ECAP process, and comparable to that produced via $\mathrm{Cu}$ tips after ECAP process. $\mathrm{Cu}-1 \% \mathrm{Cr}$ Electrode after ECAP process showed less deformation in comparison with $\mathrm{Cu}$ and $\mathrm{Cu}-1 \% \mathrm{Cr}$ before ECAP process. The complete features of RSW nugget for stainless steel welds using $\mathrm{Cu}-1 \% \mathrm{Cr}$ electrode tips after ECAP shows columnar grains and very thin area of heat affected zone (HAZ) and nugget formation with fewer defects for the joining of stainless steel welds using electrode tips are observed.

\section{REFERENCES}

[1] S. J. Oh, S. B Kang, "Analysis of the billet deformation during Equal channel angular pressing”, Mater. Sci. Eng. A343,107-117, 2003.

[2] V. M. Segal "Material processing by simple shear", Mater.Sci.Eng. A197,157-164. 1995

[3] Y.I. Iwahashi, Z. Horita,. M. Nemoto, T.G. Langdon, "Investigation of microstructural evolution during Equal channel angular pressing “, Acta. Mater. Vol.45 ,4733-4740,1997.

[4] A. A. Aljboury, L.B., Hussain, N. M. Sharif, M. Z. Addullah "The influence of plastic Deformation Via ECAP on the Hardness of 6061 Al alloy", UM, KL, Malaysia, paper 67, session 15, ICRAMME 2005.

[5] S. Lee., A. Utsunomiya, A. H.kamatsu, K. Neishi, M.Furukaw, Z.Horita, T.G. Langdon,” Influence of scandium and zirconium on grain stability and super plastic ductility in ultra fine grained Al-Mg alloys" Acta. Mater.,Vol.50, 553-.560, 2002.

[6] H. S. Kim, Finite element analysis of equal channel angular pressing using a round corner die" Mater. Sci. Eng., A315, 122-128, 2001.

[7] D. W. Dickinson, Resistance Spot Welding, Metals Handbook, Nint Edition, Vol. 6, Welding, Brazing, and Soldering, Welding Rolled Research \& Development, Republic Steel Corp. pp. 469, 493, 1983. 
[8] W. H. Kearns, "Welding Handbook, Resistance and Solid State Welding and Others Joining Processes", 7th Edition, American Welding Society, 2501 Northwest 7th Street, Miami, Florida 33125, Vol. 3, pp. 99,128,131,132(1980),

[9] V.M Segal., "Equal channel angular extrusion: from macromechanics to structure formation". Mat. Sci. Eng. A271, 322-333. 1999.

[10] Y. Wu, I. Baker, "An experimental study of equal channel angular extrusion” Scripta Mater. Vol. 37, 347-353, 1997.

[11] A. Shan, I.G. Moon, H.S. Jo, J.W. Park "Direct observation of shear deformation during equal channel angular pressing of pure Aluminum", Scripta Mater., Vol. 41, 353-364, 1999.

[12] Y.I Wahashi, J. Wang, Z. Horita, M. Nemoto, and T. G. Langdon, "Principle of equal channel angular pressing of ultra fine grained materials" Scripta Mater., Vol.35, part 2, 143146,1996 . 